\title{
Prevalence of ocular surface disease in patients with glaucoma on topical medications
}

\author{
Vijaya Pai H' ${ }^{1}$, L Satya Hareesh Reddy ${ }^{1}$ \\ 'Department of Ophthalmology, Kasturba Medical College, Manipal Academy of \\ Higher Education, Manipal, Karnataka, India
}

\begin{abstract}
Aim: To compare the prevalence of ocular surface disease (OSD) in patients using antiglaucoma medications vs normal subjects.

Design: Prospective observational study.

Method: A total of 94 patients with glaucoma on topical medications were included in the study group. Age- and gender-matched normal subjects $(n=94)$ formed the control group. They were assessed for OSD using ocular surface disease index (OSDI) questionnaire, tear break-up time (TBUT), Lissamine green staining, and Schirmer's test.

Results: The prevalence of OSD was significantly more in the study group (72.4\%) when compared to controls (44.6\%) using the OSDI questionnaire. Schirmer's test showed $84 \%$ patients had decreased tear production in the study group vs $53 \%$ in controls. TBUT was abnormal in $67.1 \%$ of the study group and of $47.8 \%$ controls. Lissamine green staining was positive in $36.2 \%$ of patients in the study group and $31.8 \%$ of controls.

Conclusion: OSD was more common in patients using intraocular pressure (IOP)-lowering drugs than in controls. Long-term therapy and multiple medications were associated with severe OSD.
\end{abstract}

Keywords: antiglaucoma medications; dry eye; ocular surface disease index (OSDI); preservatives

\section{Introduction}

Topical hypotensive medications remain the standard form of therapy for glaucoma. Intraocular pressure (IOP)-lowering medications are multidose medications and include preservatives to prevent microbial contamination and biodegradation, thus maintaining drug potency and prolonging its shelf life. ${ }^{1,2}$

As glaucoma is a disease of the elderly, they are more prone to developing ocular surface disease (OSD). Prevalence of OSD in people over 40 years is $2.1 \%$, ranging from $0.3 \%$ in people aged 40 years to $3.3 \%$ in people aged 70 years. ${ }^{3}$ Glaucoma patients have to be treated with topical medications that contain preservatives and cause increased tear evaporation, inducing an immunological and/or toxic response from the ocular surface. ${ }^{4}$

Correspondence: Dr. Vijaya Pai H, Department of Ophthalmology, Kasturba Medical College, Manipal Academy of Higher Education, Manipal, 576104, India.

E-mail:paivijaya@yahoo.co.in 


\section{Methods}

This was a prospective observational study conducted at a tertiary care center during the period between August 2013 and September 2015. Patients with glaucoma $(n=94)$ formed the study group; age- and gender-matched normal subjects $(n=94)$ who were not on any topical medications formed the control group. Sample size was estimated based on the minimum expected prevalence of $40 \%$ (based on the literature). In order to estimate this prevalence with $25 \%$ allowable error and $95 \%$ confidence, the required sample size was estimated to be a minimum of 93 .

The study was cleared by the institutional ethical committee. Patients with primary open angle glaucoma, primary angle closure glaucoma, combined mechanism glaucoma, pseudoexfoliation, and pigment dispersion glaucoma using topical antiglaucoma medications for more than six months were recruited. Patients who were using topical medications like steroids and lubricants, those who had undergone any ocular surgery, and patients with lens-induced glaucoma and glaucoma secondary to uveitis were excluded from the study. Information regarding the number of eye medications for glaucoma and duration of treatment was collected.

Patients were assessed for OSD using the following tests in the order given below.

1. Ocular surface disease index questionnaire (OSDI)

The OSDI is a disease-specific questionnaire used to quantify the specific impact of dry eye on vision related quality of life. The total OSDI score is calculated using the formula:

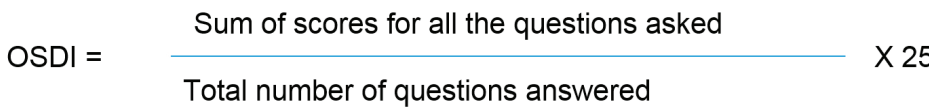

Using OSDI scores, patients were categorized as: normal (score 0-12), mild symptoms (13-22), moderate symptoms (23-32), and severe symptoms (33-100). ${ }^{5}$

2. Tear film break-up time (TBUT)

TBUT was evaluated by measuring the interval between the last blink and the appearance of the first area of tear film break-up on the corneal tear film using a cobalt blue filter on the slit lamp microscope. The results were graded as: more than $\geq 10$ seconds: normal; $5-9$ seconds: mild to moderate; $<5$ seconds: severe

3. Lissamine green staining of cornea and conjunctiva Lissamine green staining was done by instilling one drop of Lissamine green into the lower conjunctival sac. Staining of the ocular surface was evaluated 
after 30 seconds but before 2 minutes had elapsed after the instillation. It was graded using the Oxford Scheme as: 0-1: normal; 2-3: mild to moderate; and 4-5: severe.

4. Schirmer's test

Schirmer's test 1 (without anaesthesia) was done by placing a Whatmann no. 41 filter paper in the lower cul-de-sac over the junction of the outer and middle third of the lower lid. Readings were noted after five minutes. Values were classified as: above $10 \mathrm{~mm}$ : normal; 6 to $10 \mathrm{~mm}$ : mild to moderate; and $<5 \mathrm{~mm}$ : severe tear deficiency.

\section{Results}

A total of 94 patients with glaucoma and 94 controls were included in the study. Among the patients with glaucoma, 61 (64.9\%) were males and 33 (35.1\%) were females. Among controls, 61 (64.9\%) were males and 33 (35.1\%) were females.

Mean age of the glaucoma patients was $63.5 \pm 10$ years, ranging from 26 to 92 years. Mean age of controls was $62.3 \pm 10.7$ years, ranging from 29 to 82 years. Twenty-six patients $(27.7 \%)$ were on treatment for less than or equal to one year, 37 patients (39.4\%) for 2-5 years, 20 patients (21.3\%) for 6-10 years, and 11 patients (11.7\%) were on treatment for more than 10 years.

Among glaucoma patients, 68 (72.4\%) patients had symptoms of OSD on the OSDI questionnaire. Of those, 62 patients (66\%) had mild to moderate symptoms and 6 patients (6.4\%) had severe symptoms. Schirmer's test showed decreased tear production in 79 patients (84\%). Among them, 44 patients (46.8\%) had mild to moderate decrease in tear production while severe deficiency was seen in 35 patients (37.2\%). TBUT was abnormal in 63 patients $(67.1 \%)$. Lissamine green staining was positive in 34 patients (36.2\%), of which 33 patients $(35.1 \%)$ had mild to moderate staining and 1 patient $(1.1 \%)$ had severe staining (Table 1 ).

Table 1. Tests results of patients on topical IOP lowering medications

\begin{tabular}{|l|l|l|l|l|}
\hline Results & OSD (\%) & $\begin{array}{l}\text { Schirmer's } \\
\text { test (\%) }\end{array}$ & TBUT (\%) & $\begin{array}{l}\text { Lissamine } \\
\text { green } \\
\text { staining (\%) }\end{array}$ \\
\hline Normal & 27.7 & 16 & 33 & 63.8 \\
\hline $\begin{array}{l}\text { Mild- } \\
\text { Moderate }\end{array}$ & 66 & 46.8 & 62.8 & 35.1 \\
\hline Severe & 6.4 & 37.2 & 4.3 & 1.1 \\
\hline
\end{tabular}

Fifty-two patients were on treatment with more than one antiglaucoma medication. With increased number of medications, from one or two to three or four, the mean OSDI score increased from mild (19.6) to moderate (23.1), respectively, 
although it was not statistically significant $(p=0.183$, independent sample t-test) (Table 2).

Table 2. Mean OSDI score in relation to number of medications

\begin{tabular}{|l|l|l|l|}
\hline Number of drugs & $\begin{array}{l}\text { Number of } \\
\text { patients }\end{array}$ & Mean OSDI score & Std deviation \\
\hline 1 to 2 & 79 & 19.6203 & 9.59 \\
\hline 3 to 4 & 15 & 23.1333 & 7.36 \\
\hline
\end{tabular}

$\mathrm{P}=0.183$, Independent sample t-test

The mean OSDI score in patients using medications for less than five years was 16.5, indicating mild OSD, and in patients using medications for more than five years it was 27.1 , indicating moderate OSD. The difference $(p=0.00)$ was statistically significant (Independent sample t-test) (Table 3). With increased duration of treatment and number of medications, test results became more positive (Tables 4-7).

Table 3. Mean OSDI score in relation to treatment duration

\begin{tabular}{|l|l|l|l|}
\hline $\begin{array}{l}\text { Treatment } \\
\text { duration }\end{array}$ & $\begin{array}{l}\text { Number of } \\
\text { patients }\end{array}$ & Mean OSDI score & Std deviation \\
\hline$<5$ years & 62 & 16.5806 & 8.33 \\
\hline$>5$ years & 32 & 27.1562 & 6.93 \\
\hline
\end{tabular}

$P=0.000$, Independent sample t-test

Table 4. Correlation between treatment duration and tests

\begin{tabular}{|c|c|c|c|c|c|c|c|}
\hline \multirow{2}{*}{$\begin{array}{l}\text { Treatment } \\
\text { duration } \\
\text { (years) }\end{array}$} & \multirow{2}{*}{$\begin{array}{l}\text { Number } \\
\text { of } \\
\text { patients }\end{array}$} & \multicolumn{3}{|l|}{ OSDI\% } & \multicolumn{3}{|c|}{ Schirmer's test \% } \\
\hline & & Normal & $\begin{array}{l}\text { Mild- } \\
\text { moderate }\end{array}$ & Severe & Normal & $\begin{array}{l}\text { Mild- } \\
\text { moderate }\end{array}$ & Severe \\
\hline$\leq 1$ & 26 & $\begin{array}{l}17 \\
65.4 \%\end{array}$ & $\begin{array}{l}9 \\
34.6 \%\end{array}$ & $\begin{array}{l}0 \\
0 \%\end{array}$ & $\begin{array}{l}10 \\
38.5 \%\end{array}$ & $\begin{array}{l}9 \\
34.6 \%\end{array}$ & $\begin{array}{l}7 \\
26.9 \%\end{array}$ \\
\hline $2-5$ & 37 & $\begin{array}{l}8 \\
21.6 \%\end{array}$ & $\begin{array}{l}29 \\
78.4 \%\end{array}$ & $\begin{array}{l}0 \\
0 \%\end{array}$ & $\begin{array}{l}4 \\
10.8 \%\end{array}$ & $\begin{array}{l}23 \\
62.2 \%\end{array}$ & $\begin{array}{l}10 \\
27 \%\end{array}$ \\
\hline $6-10$ & 20 & $\begin{array}{l}1 \\
5 \%\end{array}$ & $\begin{array}{l}17 \\
85 \%\end{array}$ & $\begin{array}{l}2 \\
10 \%\end{array}$ & $\begin{array}{l}1 \\
5 \%\end{array}$ & $\begin{array}{l}10 \\
50 \%\end{array}$ & $\begin{array}{l}9 \\
45 \%\end{array}$ \\
\hline$>10$ & 11 & $\begin{array}{l}0 \\
0 \%\end{array}$ & $\begin{array}{l}7 \\
63.6 \%\end{array}$ & $\begin{array}{l}4 \\
36.4 \%\end{array}$ & $\begin{array}{l}0 \\
0 \%\end{array}$ & $\begin{array}{l}2 \\
18.2 \%\end{array}$ & $\begin{array}{l}9 \\
81.8 \%\end{array}$ \\
\hline
\end{tabular}


Table 5. Results of TBUT and Lissamine green staining in relation to treatment duration

\begin{tabular}{|l|l|l|l|l|l|l|l|}
\hline $\begin{array}{l}\text { Treatment } \\
\text { duration } \\
\text { (years) }\end{array}$ & $\begin{array}{l}\text { Number } \\
\text { of } \\
\text { patients }\end{array}$ & \multicolumn{2}{|l|}{ TBUT (\%) } & \multicolumn{2}{l|}{ Lissamine Green staining (\%) } \\
\hline & & Normal & $\begin{array}{l}\text { Mild- } \\
\text { moderate }\end{array}$ & Severe & Normal & $\begin{array}{l}\text { Mild- } \\
\text { moderate }\end{array}$ & Severe \\
\hline$\leq 1$ & 26 & 19 & 7 & 0 & 25 & 1 & 0 \\
\hline $2-5$ & 37 & 11 & $26.9 \%$ & $0 \%$ & $96.2 \%$ & $3.8 \%$ & $0 \%$ \\
\hline $6-10$ & 20 & 1 & 26 & 0 & 30 & 7 & 0 \\
\hline$>10$ & 11 & 0 & $70.3 \%$ & $0 \%$ & $81.1 \%$ & $18.9 \%$ & $0 \%$ \\
\hline & & $0 \%$ & $63.6 \%$ & $36.4 \%$ & $0 \%$ & $90.9 \%$ & $9.1 \%$ \\
\hline
\end{tabular}

Table 6. Correlation between number of drugs and OSDI, Schirmer's test

\begin{tabular}{|l|l|l|l|l|l|l|l|}
\hline $\begin{array}{l}\text { Number } \\
\text { of drugs }\end{array}$ & $\begin{array}{l}\text { Number } \\
\text { of } \\
\text { patients }\end{array}$ & \multicolumn{2}{|l|}{ OSDI (\%) } & \multicolumn{2}{l|}{ Schirmer's test (\%) } \\
\hline & & Normal & $\begin{array}{l}\text { Mild- } \\
\text { moderate }\end{array}$ & Severe & Normal & $\begin{array}{l}\text { Mild- } \\
\text { moderate }\end{array}$ & Severe \\
\hline 1 & 42 & 16 & 25 & 1 & 7 & 23 & 12 \\
& & $38.1 \%$ & $59.5 \%$ & $2.4 \%$ & $16.7 \%$ & $54.8 \%$ & $28.6 \%$ \\
\hline 2 & 37 & 7 & 25 & 5 & 5 & 12 & 20 \\
\hline 3 & 13 & 3 & 10 & 0 & 3 & 9 & $54 \%$ \\
\hline 4 & $23.9 \%$ & $67.6 \%$ & $13.5 \%$ & $13.5 \%$ & $32.4 \%$ & 1 \\
& & 0 & 2 & $0 \%$ & $23.1 \%$ & $69.2 \%$ & $7.7 \%$ \\
\hline & & $0 \%$ & $100 \%$ & $0 \%$ & $0 \%$ & 0 & 2 \\
\hline
\end{tabular}

Table 7. Correlation between number of drugs and TBUT, Lissamine green staining

\begin{tabular}{|l|l|l|l|l|l|l|l|}
\hline $\begin{array}{l}\text { Number } \\
\text { of drugs }\end{array}$ & $\begin{array}{l}\text { Number } \\
\text { of } \\
\text { patients }\end{array}$ & \multicolumn{2}{|l|}{ OSDI (\%) } & \multicolumn{2}{l|}{ Schirmer's test (\%) } \\
\hline & & Normal & $\begin{array}{l}\text { Mild- } \\
\text { moderate }\end{array}$ & Severe & Normal & $\begin{array}{l}\text { Mild- } \\
\text { moderate }\end{array}$ & Severe \\
\hline 1 & 42 & 21 & 21 & 0 & 34 & 8 & 0 \\
\hline 2 & 37 & 7 & 27 & $2.4 \%$ & $81 \%$ & $19 \%$ & $0 \%$ \\
\hline & $18.9 \%$ & $73 \%$ & $\begin{array}{l}3 \\
8.1 \%\end{array}$ & $\begin{array}{l}19 \\
51.4 \%\end{array}$ & $\begin{array}{l}17 \\
45.9 \%\end{array}$ & $\begin{array}{l}1 \\
2.7 \%\end{array}$ \\
\hline
\end{tabular}


OSD in patients with glaucoma on topical medications

\begin{tabular}{|l|l|l|l|l|l|l|l|}
\hline $\begin{array}{l}\text { Number } \\
\text { of drugs }\end{array}$ & $\begin{array}{l}\text { Number } \\
\text { of } \\
\text { patients }\end{array}$ & \multicolumn{2}{|l|}{ OSDI (\%) } & \multicolumn{2}{l|}{ Schirmer's test (\%) } \\
\hline & & Normal & $\begin{array}{l}\text { Mild- } \\
\text { moderate }\end{array}$ & Severe & Normal & $\begin{array}{l}\text { Mild- } \\
\text { moderate }\end{array}$ & Severe \\
\hline 3 & 13 & 3 & 9 & 1 & 7 & 6 & 0 \\
\hline 4 & $23.1 \%$ & $69.2 \%$ & $7.7 \%$ & $53.8 \%$ & $46.2 \%$ & $0 \%$ \\
\hline & 0 & 2 & 0 & 0 & 2 & 0 \\
$100 \%$ & $0 \%$ & $0 \%$ & $100 \%$ & $0 \%$ \\
\hline
\end{tabular}

Among controls, $42(44.6 \%)$ patients had symptoms of OSD on the OSDI questionnaire. Of those, $40.4 \%$ had mild to moderate symptoms and $4.25 \%$ had severe symptoms. Schirmer's test showed 50 patients (53\%) with decreased tear production. TBUT was abnormal in 45 patients (47.8\%). Lissamine green staining was positive in 30 patients (31.8\%) (Table 8 ).

Table 8. Test results of controls

\begin{tabular}{|l|l|l|l|l|}
\hline Results & OSDI \% & $\begin{array}{l}\text { Schirmer's } \\
\text { test \% }\end{array}$ & TBUT \% & $\begin{array}{l}\text { Lissamine } \\
\text { green } \\
\text { staining \% }\end{array}$ \\
\hline Normal & $55.3 \%$ & $46.8 \%$ & $52.1 \%$ & $68.0 \%$ \\
\hline Mild-moderate & $40.4 \%$ & $38.2 \%$ & $36.1 \%$ & $29.7 \%$ \\
\hline Severe & $4.2 \%$ & $14.8 \%$ & $11.7 \%$ & $2.1 \%$ \\
\hline
\end{tabular}

\section{Discussion}

The ocular surface is one of the most complex tissues in the body as it is not protected by skin, which is the body's most valuable defence against both desiccation and infection. The stability of the ocular surface provides protection and a refractive surface that allows for good-quality vision. The tear film is fundamental in the maintenance of the ocular surface. Any condition that adversely affects the stability and function of the tear film may result in unstable tear film and OSD onset.

As defined by the International Dry Eye Workshop (DEWS), ${ }^{6}$ dry eye is a multifactorial disease that results in:

1. symptoms of discomfort;

2. visual disturbance;

3. tear film instability;

4. potential damage to the ocular surface;

5. increased osmolarity of the tear film; and

6. inflammation of the ocular surface. 
Dry eye disease is of two types: aqueous tear-deficient dry eye (ADDE) and evaporative dry eye (EDE).

OSD is a common comorbidity in patients with glaucoma due to the fact that its prevalence increases with age as in glaucoma. OSD is known to occur in approximately $15 \%$ of the general elderly population and is reported in $48 \%$ to $59 \%$ of patients treated with topical antiglaucoma medications. ${ }^{1,7,8}$ One in six patients with glaucoma has OSD symptoms severe enough that they need some form of treatment for OSD.

The German Glaucoma and Dry Eye Register ${ }^{9}$ reported that the incidence of dry eye increases with age and among women. We had a greater number of males in the study group. The severity of OSD among males and females was not statistically different. (Chi square test/ Fisher exact test $p=0.142$ ). They reported increased prevalence of dry eye with long-term use of multiple topical antiglaucoma medications, a similar observation made in our study.

Barisic et al. ${ }^{10}$ observed that $75 \%$ of patients had symptoms of OSD using the OSDI questionnaire. Of those, $17 \%$ had scores in accordance with mild OSD, $11 \%$ had moderate OSD, and $47 \%$ had severe OSD. The overall prevalence was similar to our study (72.4\%). In our study, we had more patients with mild to moderate symptoms. However, they had more patients with severe symptoms (47\%) when compared to our study (6.4\%).

Vinutha et al. ${ }^{11}$ observed that $32 \%$ of patients reported symptoms in at least one eye on the OSDI questionnaire, which was less when compared to our study. TBUT (74\%) (mild to moderate: 54\%; and severe: $20 \%$ ) and Lissamine green staining (47\%) results were more positive in their study when compared to our study. Schirmer's test showed more positive results in our study (total: $84 \%$; mild to moderate: $46.8 \%$; severe: $37.2 \%$ ) when compared to their study (total: $72 \%$; mild to moderate: $50.5 \%$; severe: $21.5 \%$ ). They also reported that with increased treatment duration and number of medications more patients became symptomatic and test results became abnormal. Our observation was similar to their study.

Leung et al.' examined the prevalence of OSD using the OSDI questionnaire, TBUT, Lissamine green staining, and Schirmer's test. In their study, 60 patients (59\%) had symptoms of OSD in the OSDI questionnaire, less than our study (72.4\%). Twenty-seven patients (27\%) had severe symptoms in their study, more than in our study. They observed that the use of more BAK-containing drops was significantly associated with higher prevalence of abnormal results on Lissamine green staining (22\%). None of them had severe staining with Lissamine green. In our study, Lissamine green staining was positive in 34 patients (36.2\%) and only one patient had severe staining. Similar to the findings by Leung et al., ${ }^{1}$ we found that with increased number of medications test results became more positive. We were not able to comment on the preservatives in the medication because of the 
wide range of eye drops being sold by different pharmaceutical companies in our country.

Fechtner et al. ${ }^{8}$ used the OSDI to describe the prevalence of OSD among patients treated for glaucoma and found that $48.4 \%$ of the patients had mild to severe symptoms, which was significantly less when compared to our study, where $72.4 \%$ patients had symptoms of OSD. Patients on one medication had a mean OSDI score of $12.9 \pm 13.1$, which was significantly lower when compared to patients on two $(16.7 \pm 17.0 ; P=0.007)$ or three medications $(19.4 \pm 18.1 ; P=0.0001)$. This was similar to our study, where with increased number of medications from one or two to three or four, the mean OSDI score increased from mild (19.6) to moderate (23.1), respectively, although it was not statistically significant $(p=0.183)$.

In a study published by Garcia-Feijoo et al., ${ }^{12}$ the overall prevalence rate of OSD was $59.2 \%$, with $25.7 \%$ having mild symptoms, $13.2 \%$ with moderate symptoms, and $20.3 \%$ with severe symptoms on the OSDI questionnaire, which is lower compared to our study. Patients on treatment for less than six years had a significantly lower mean OSDI score (18: mild OSD) when compared to patients on treatment for six years or more (23: moderate OSD; $P=0.03$ ). With increased number of medications from one or two medications to three or four medications, the mean OSDI score increased from mild to moderate, although the difference in scores was not statistically significant $(P=0.15)$. In our study, mean OSDI scores in patients using medications for less than five years was 16.5 , indicating mild OSD, while in patients using medications for more than five years it was 27.1, indicating moderate OSD. This difference $(p=0.00)$ was statistically significant and correlated with their study.

The effect of preservatives in antiglaucoma medications on the ocular surface and their role in causation of OSD has been greatly investigated. However, we did not study the preservatives in the medications used by the study group.

The differences among the prevalence of OSD in different studies could be due to differences in methodology, severity of disease, age, duration of therapy, and the type and number of medications used. The severity of dry eye was more evident with TBUT and Schirmer's test as compared to Lissamine green staining.

In the studies mentioned above, only Leung et al. and Vinutha et al. used methods such as the OSDI questionnaire for subjective analysis, Schirmer's test for tear production, TBUT for Meibomian gland function, and Lissamine green surface staining to asses OSD. In our study, we also used all the methods to assess OSD and compared it with the age-matched controls. This helped us to assess them along with glaucoma patients, helping to compare the effect of glaucoma medications in the occurrence of OSD. 


\section{Conclusion}

From our study, we conclude that almost $75 \%$ of the patients with glaucoma experienced some level of OSD. OSD was more common in patients using IOP-lowering drugs than controls, indicating that antiglaucoma medications contribute to its occurrence. There was a statistically significant correlation between increased treatment duration and worsening of OSD symptoms. Further, with increased number of topical medications, there was a clinically relevant increase in OSD symptom severity. Finally, OSD can influence treatment adherence and success, thus greatly influencing the quality of life of the glaucoma patients though we did not study this aspect of glaucoma medications. Educating patients about adverse effects of drugs and recommending them to avoid environmental circumstances such as dry air and long working hours in front of the computer play a crucial role in glaucoma management. Patients may enjoy a healthier ocular surface and better quality of life by switching over to medications with a smaller percentage of BAK or BAK-free.

Further studies that compare the effects of BAK and BAK-free agents on OSD are needed to validate the beneficial influence of BAK-free agents.

\section{References}

1. Leung EW, Medeiros FA, Weinreb RN. Prevalence of ocular surface disease in glaucoma patients. J Glaucoma. 2008;17(5):350-355.

2. Baudouin C. Detrimental effect of preservatives in eye drops: implications for the treatment of glaucoma. Acta Ophthalmol. 2008;86(7):716-726.

3. European Glaucoma Society, Terminology and guidelines for glaucoma. In: European Glaucoma Society Guidelines. 3rd ed. Savona, Italy: Editrice Dogma; 2008;117-153.

4. Baudouin C, Labbé A, Liang H, Pauly A, Brignole-Baudouin F. Preservatives in eye drops: the good, the bad and the ugly. Prog Retin Eye Res. 2010;29(4):312-334.

5. Schiffman RM, Christianson MD, Jacobsen G, Hirsch JD, Reis BL. Reliability and validity of the ocular surface disease index. Arch Ophthalmol. 2000;118(5):615-621.

6. Lemp MA, Foulks GN. The definition and classification of dry eye disease. The Ocular Surface. 2007;5(2):75-92.

7. Schein OD, Muño B, Tielsch JM, Bandeen-Roche K, West S. Prevalence of dry eye among the elderly. Am J Ophthalmol. 1997;124(6):723-728.

8. Fechtner RD, Godfrey DG, Budenz D, Stewart JA, Stewart WC, Jasek MC. Prevalence of ocular surface complaints in patients with glaucoma using topical intraocular pressure-lowering medications. Cornea. 2010; 29(6):618-621.

9. Baudouin C. The ocular surface in glaucoma. Cornea. 2009;28(11):S14-9.

10. Barisic F, Krolo I, Popovic- Suic S, et al. Prevalence of ocular surface disease in patients with glaucoma using topical antiglaucoma medications. J Clin Exp Ophthalmol. 2014;5:334.

11. Niveditha $\mathrm{H}$, Vinutha BV, Himamshu NV, et al. Prevalence of ocular surface disease in glaucoma patients using anti-glaucoma medications. Journal of Evolution of Medical and Dental Sciences. 2013;2(23):4308-4314.

12. Garcia-Feijoo J, Sampaolesi JR. A multicenter evaluation of ocular surface disease prevalence in patients with glaucoma. Clin Ophthalmol. 2012;6:441-446. 